\title{
Study on Identification Procedure for Unidentified Underwater Targets Using Small ROV Based on IDEF Method
}

\author{
Hyuk Baek $\circledast^{*}$, Bong-Huan Jun $\circledast^{*}$, Suk-Min Yoon $\circledast^{*}$ and Myounggyu Noh $\circledast^{* *}$ \\ *Ocean Equipment Research Department, KRISO, Daejeon, Korea \\ ** Department of Mechatronics Engineering Chungnam National University, Daejeon, Korea

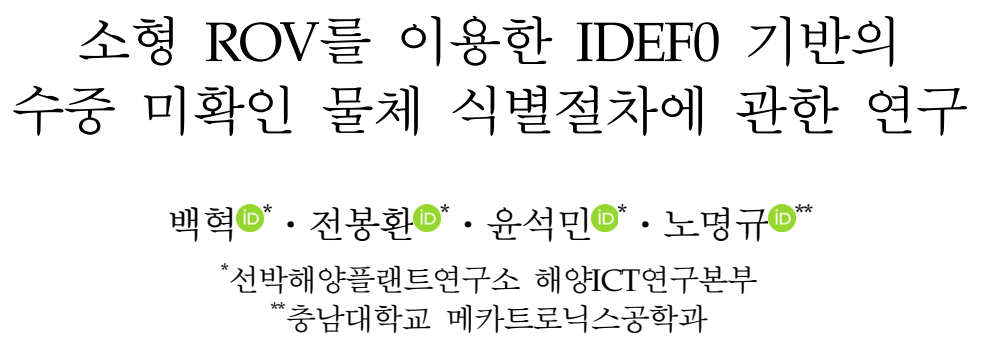

KEY WORDS: Remotely operated vehicle(ROV) 원격조종 무인잠수정, Operation procedure 운용절차, West sea 서해, IDEF

\begin{abstract}
Various sizes of ROVs are being utilized in offshore industrial, scientific, and military applications all around the world. Because of innovative developments in science and technology, image acquisition devices such as sonar devices and cameras have been reduced in size and their performance has been improved. Thus, we can expect better accuracy and higher resolution even in the case of exploration using a small ROV. The purpose of this paper is to prepare a standard procedure for the identification of unidentified hazardous materials found during the National Oceanographic Survey. In this paper, we propose an IDEF (Integrated DEFinition) method modeling technique to identify unidentified targets using a small ROV. In accordance with the proposed procedure, an ROV survey was carried out on target No.16 with a four-ton-class fishing boat as a support vessel on September 18th of 2018 in the sea near Daebu Island. Unidentified targets, which were not known by the multi-beam data obtained from the ship, could be identified as concrete pipes by analyzing the HD camera and high-resolution sonar images acquired by the ROV. The whole proposed procedure could be verified, and the survey with the small ROV required about 10 days to identify the target in one place.
\end{abstract}

\section{1. 개 요}

우리나라에서는 1982년 12월에 채택된 유엔해양법협약에 따른 주권 해역의 과학적 조사 자료를 확보하고, 해양 부존자원 및 에 너지 개발 등 해양 개발을 위한 기초자료 제공, 해상교통의 안전 항로 확보, 해양환경 보존 및 해양 정책 수립 등에 필요한 정보를 제공할 목적으로 국립해양조사원에서 1996년부터 연차적으로 국 가해양기본도조사를 실시해 왔다. 수로는 한국해양조사원에서 지속적으로 해도를 제작 및 구축하고 있다(Doopedia, 2019).

국가해양기본도 조사에서 발견된 항해 위험물에 대한 식별은 안전 항로 확보와 해양환경 보존 측면에서 필수적이다. 또한, 미식별 위험물은 우리나라 전 해역에 걸쳐 상당수 존재하고 있
어 이를 식별할 표준 절차와 로드맵 작성이 선행되어야 한다. 본 연구에서는 소형 ROV(Remotely operated vehicle, 무인잠수 정)를 이용한 해저 미확인 물체의 식별에 필요한 하드웨어, 소 프트웨어, 사람 등을 표준화된 방법으로 절차를 작성 및 관리하 기 위해 IDEF0(Integrated DEFinition 0) 기능 모델링 방법(Function modeling method)을 채용했다. IDEF0 방법은 조직이나 시스템의 의사결정, 행동, 활동을 모델링 할 수 있도록 디자인 되어 관련 된 사람들 간의 의사소통을 촉진하고 활동에 관한 업무의 흐름 을 명확하게 표현할 수 있는 장점이 있다(Dynamic Soft Inc., 2011). 이러한 방법을 사용하여 ROV 운영회사마다 각기 다른 석유생산기지의 철골구조물 안전도 검사의 표준절차를 제안하 여 보다 효율적인 관리를 수행하고자 한 선행연구 사례가 있다

Received 26 February 2019, revised 11 April 2019, accepted 13 June 2019

Corresponding author Suk-Min Yoon: +82-42-866-3882, smyoon@kriso.re.kr ORCID: https://orcid.org/0000-0002-3523-3221

It is a recommended paper from the proceedings of 2018 autumn workshop of the Korea Marine Robot Technology (KMRTS) which is one of the divisions belong to the Korean Society of Ocean Engineers (KSOE). 
(Rocha and Tome, 2015).

본 논문의 2장에서는 IDEF0 기능 모델링 방법으로 소형 ROV 를 이용한 항해 위험물의 시범조사 절차에 대해서 제안했고, 3 장에서는 제안한 절차를 이용하여 2018년 9월 18일 대부도 앞 바다에서 4톤급 낚시어선을 지원모선으로 위험물(No. 16)에 대 한 소형 ROV 조사 수행결과를 나타냈다. 4장 결론에서는 $\mathrm{IDEF} 0$ 모델링 기법으로 설계한 절차에 대해서 실제 적용평가 결과 및 향후 관리방안에 대하여 작성하였다.

\section{IDEFO 방법}

\subsection{IDEF0란?}

$\mathrm{IDEF} 0$ 는 1970년대 미 공군의 ICAM(Integrated computer aided manufacturing) 프로젝트 일환으로 개발된 기능 모델링 방 법으로 시스템의 획득, 분석, 설계, 실험을 지원하는데 필요한 활동을 모형화하기 위하여 고안되었다. 따라서 $\mathrm{IDEF} 0$ 는 조직화 된 접근법으로 현존하거나 계획된 시스템의 역할과 역할들 간 의 관계를 표현한 것으로 사람들 간의 의사소통 및 이해를 원 활히 하기 위한 수단으로 사용된다(The National Institute of Standards and Technology, 1993).

Fig. 1은 IDEF0 모델의 상단 레벨이며 시스템에 대한 가장 일 반적인 설명으로 네 가지 화살표 ICOM(Input, Control, Output, Mechanism)으로 나타낸다. 가운데 상자는 활동, 절차, 운영 등 사람, 기계, 컴퓨터 등에 의해 수행되는 기능(Function)을 나타낸 다. ICOM의 Input은 기능을 수행하는데 필요한 객체 혹은 데이 터를 나타낸다. Control은 기능의 수행을 통제하는 규정, 표준 등을 나타내며, Output은 Function에 의해 만들어지는 객체 혹은 데이터이다. 마지막 Mechanism은 기능을 수행하는 사람 또는 개체 혹은 프로그램 등을 나타낸다(Ismail et al., 2010).

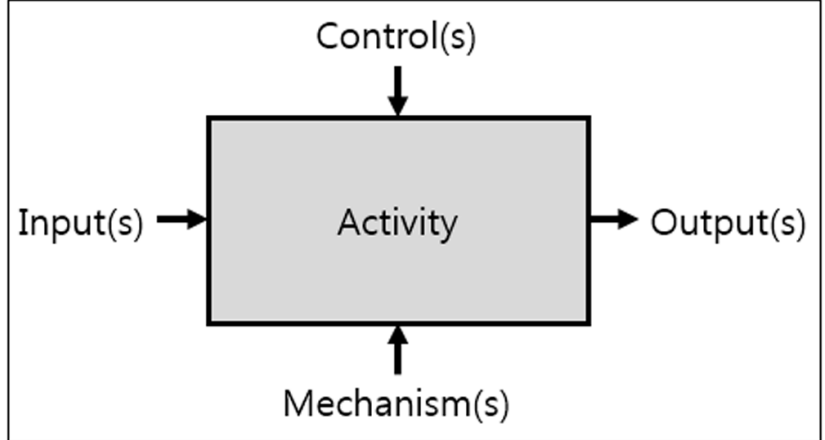

Fig. 1 IDEF0 basic formalism

\subsection{IDEF0 방법론을 이용한 식별절차 제안}

본 논문에서 제안하는 위험물의 식별 절차를 IDEF0 모델링(개 요)으로 Fig. 2에서 나타내고 있다. 좌측에 Input 데이터로는 미식 별 위험물 위치좌표가 주어지고, 기능 상자(Underwater target identification)에 의해 식별보고서가 Output으로 나오는 구조를 가 진다. 상측의 Control에는 위험물 식별 로드맵, 기상정보 그리고, 잠수정과 센서 운영규정이 있다. 특히 위험물 식별 로드맵은 동 해, 남해, 서해의 항로와 항로인근 해저에 존재하는 식별 대상들 의 위치, 주변 환경에 대한 자료, 과업지시서 그리고, 운영 표준 절차 등을 포함한다. 하측의 Mechanism에는 과업을 지시하는 Client와 소형 ROV를 운영하는 업체로 구성된다. 운영업체는 항 법 프로그램을 운영하는 Navigator, ROV를 운영하는 Operator, 실 해역 시범조사에 투입되는 장비를 나타내는 ROV \& Sensors \& Support ship, 유속과 수심을 이용하여 소형 ROV 투입 가능여부 를 결정하는 Power \& Drag simulator, 실시간 항법데이터를 나타 내고 저장하는 Navigation software를 제공해야 한다.

Fig. 2에 나타난 한 개의 기능 상자를 분해한 하층 구조는 부록

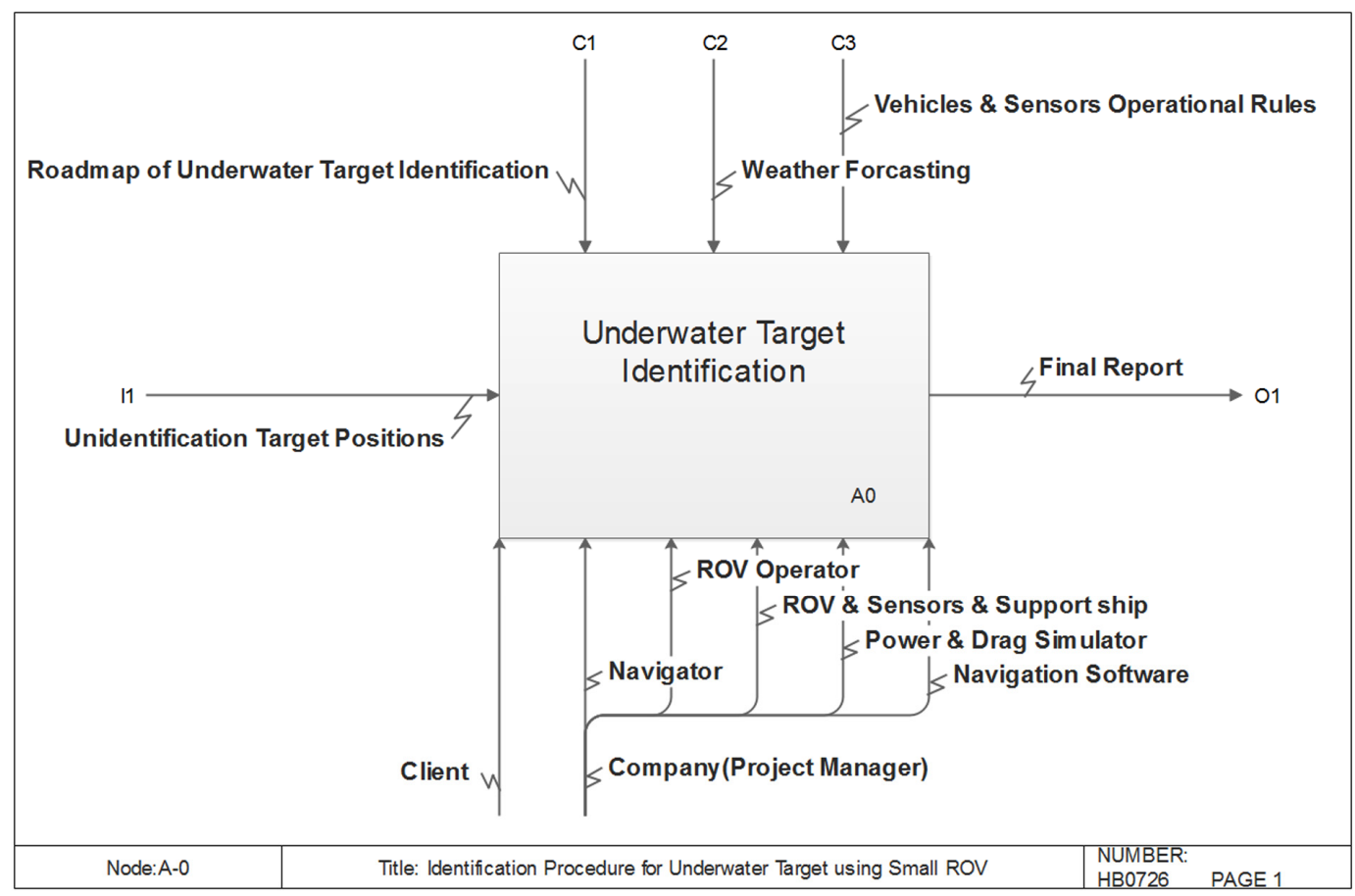

Fig. 2 IDEF modeling concept to identify unidentified objects 
$\mathrm{A}$ 의 Fig. $\mathrm{A} 1$ 의 아래 그림에서 환경평가(Environmental assessment), ROV 선정(ROV selection), 운영계획(Operational planning), ROV 운 영(ROV operating), 식별보고서 작성(Final report)으로 총 5개의 기 능 상자로 자세히 나타내고 있다. 다음의 3장에서는 실해역 조사 결과를 5 개의 기능상자 제목으로 나누어 설명한다.

\section{3. 실해역 조사 결과}

본 장에서는 국립해양조사원의 요청으로 수행한 서해 No. 16 번 위치에서 소형 $\mathrm{ROV}$ 를 이용한 위험물 식별 시범조사 결과를 5 단계로 정리했다. 시범조사는 2018년 9월 18일 인천 대부도 앞 바다에서 수행했다.

\section{1 환경평가}

첫 번째 단계인 환경평가에서는 미확인 위험물 식별 로드맵 에서 우선순위가 높은 위험물 좌표가 주어진다. 이 좌표가 있는 해역의 자료들을 수집하여 $\mathrm{ROV}$ 운영 계약자는 감독관(제 3 기관 혹은 ROV 전문가)과 함께 환경평가를 수행한다. 수집 자료로는
멀티빔데이터, 유향, 유속, 조위표, 수심정보 등이 있겠다. No. 16번 지역은 대부도 인근 해역으로 아래 Fig. 3의 좌측 구글어 스 지도에서 표시된 No. 16 지점이다.

대표적인 수집 자료를 Table 1에 정리했다. 2018년 8월 1일부터 8 월 31 일까지 인근 관측지점의 해수 유동 흐름과 조위 예측 값은 사리에서 최대유속 약 $1 \mathrm{~m} / \mathrm{s}$, 조차 $10 \mathrm{~m}$ 를 나타내고, 조금에서는 최 대유속 약 $0.5 \mathrm{~m} / \mathrm{s}$, 조차 약 $4 \mathrm{~m}$ 를 나타낸다. Table 1 의 아래 유향- 유 속과 조위 그림은 부록 $\mathrm{C}$ 의 Fig. $\mathrm{C} 1$ 에서 확대하여 나타냈다.

\subsection{ROV 선정}

본 시범조사의 환경평가 단계에서 조사된 자료를 바탕으로 조사대상 위험물의 위치, 크기, 형상, 수심 정보와 주변 해역의 유속, 탁도 정보를 입력 값으로 사용하여 ROV의 요구 성능을 정한다. 멀티빔데이터에 나타난 대상 물체는 대략 폭 2미터 길 이 5 6미터 크기의 두 개 물체로 나타났다. 서해의 탁한 시계에 서 운영하므로 광학영상 장비는 근접하여야 대상을 볼 수 있으 므로 전체 대상을 한 번에 볼 수 없는 단점이 있다. 이를 보완 하기 위해 이미징 소나가 요구된다. 특히 이미징 소나는 실시간

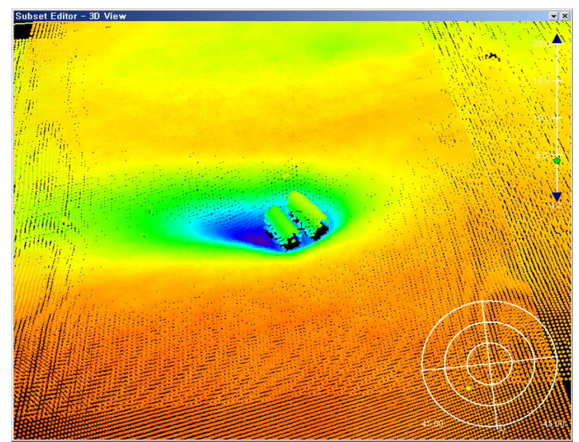

Fig. 3 Satellite image map (Left), multibeam image (Right)

Table 1 Obtained data of No. 16 point

\begin{tabular}{cccc}
\hline \hline Control number & No. 16 & Max. velocity [m/s] & 0.97 \\
Location WGS-84 & $37-18-46.74 \mathrm{~N}$ & Min. velocity [m/s] & 0.0 \\
Depth [m] & $126-34-18.87 \mathrm{E}$ & Flow direction [ $\left.{ }^{\circ}\right]$ & 52.5 \\
Ambient depth [m] & 10.4 & Turbidity $\left[\mathrm{g} / \mathrm{m}^{3}\right]$ & 2.771 \\
\hline
\end{tabular}

Current velocity and direction predictions(upper), Tide level predictions(lower)

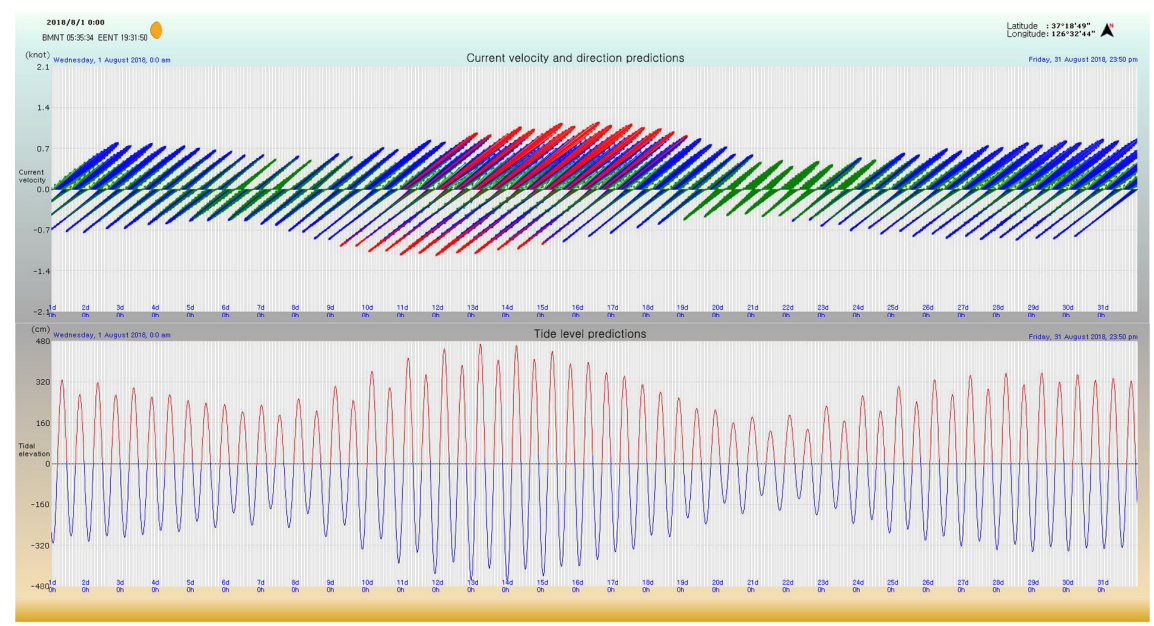


으로 소나 이미지를 보여주므로 탁한 시계에서 항법과 물체 식 별(크기, 형태)에 큰 장점이 있다. 또한, 수중 위치측정을 위한 USBL(Underwater short base line) 센서가 필요하다. 이와 함께 수중의 소형 $\mathrm{ROV}$ 운용 가능여부를 결정하는 중요한 요소는 $\mathrm{ROV}$ 추력과 항력의 관계이다. 이것은 운영방법이 결정된 상태 에서 계산이 가능하며, 본 시범조사에서는 Fig. 4와 같은 운영방 법을 채용했다. 이 운영 방법은 일반적인 소형 ROV가 해저를 조사할 때 이용하는 방법으로 전체 항력 계산에는 Tether cable 항력과 사용 $\mathrm{ROV}$ 항력 이외에는 고려하지 않는다. 두 항력의 합은 식 (1)과 같다(Robert et al., 2014).

$$
\text { Total drag }=\frac{1}{2} \sigma A_{R} V^{2} C_{d R}+\frac{1}{2} \sigma A_{T} V^{2} C_{d T}
$$

여기서, 아래첨자의 $R$ 과 $T$ 는 각각 ROV와 Tether cable을 의미하며, $\sigma$ 는 해수 밀도와 중력가속도의 비의 값으로 정의된다. $C_{d}$ 는 항력 계수로 ROV는 단면적을 고려하여 $0.8 \sim 1.0$ 의 값을 가지며, Unfaired cable의 항력 계수는 1.2 로 알려져 있다. $A$ 는 항력 계수가 작용하는 단면적이며, $V$ 는 $\mathrm{ROV}$ 와 유속의 상대속도이다.

다음의 Table 2에서는 ROV의 사양을 나타내고 있으며, 식 (1) 의 항력 계산에 필요한 케이블직경, $\mathrm{ROV}$ 단면적 크기 정보를 구할 수 있다.

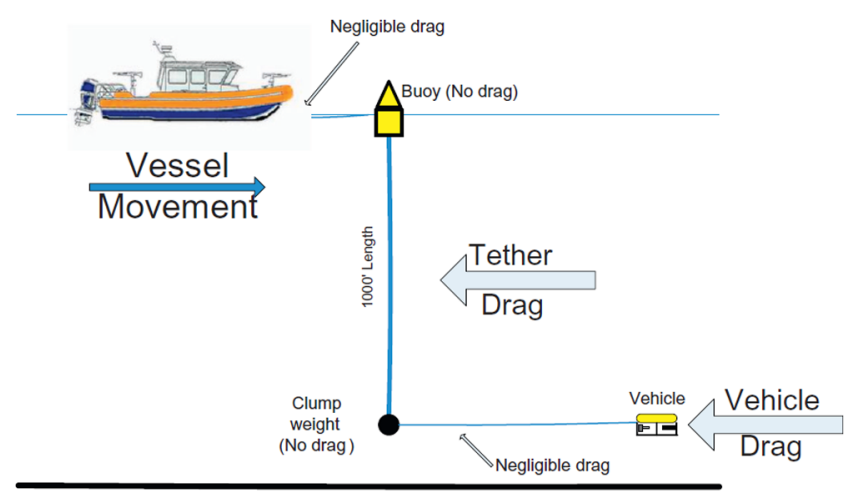

Fig. 4 Drag components of operating system

Table 2 Specifications of ROVO-2

\begin{tabular}{cc}
\hline \hline System and parameter & ROVO-2 \\
\hline Max. operation depth $[\mathrm{m}]$ & 200 \\
Length $[\mathrm{m}]$ & 0.76 \\
Width $[\mathrm{m}]$ & 0.5 \\
Height $[\mathrm{m}]$ & 0.3 \\
Weight in air $[\mathrm{kg}]$ & 20 \\
Thruster number & 6 \\
Lateral thrust & Yes \\
Propulsion force $[\mathrm{kg}]$ & 9.97 \\
Tether diameter $[\mathrm{m}]$ & 0.01 \\
Rear camera & No \\
Lateral camera & No \\
Power requirement $[\mathrm{W}]$ & 2 \\
\hline
\end{tabular}

\section{ROVO-2 CURRENT-DRAG CURVE}

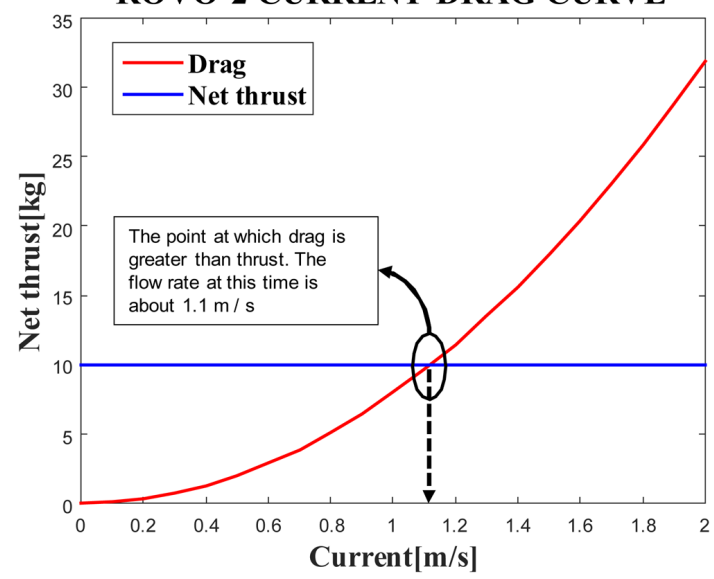

Fig. 5 Result of ROV power \& drag simulation

위의 Fig. 5에서 Power \& Drag simulation 결과를 나타냈다. ROVO-2 모델의 추력은 사양에 의해 $9.97 \mathrm{~kg}$ 으로 나타났으며, 항 력은 식 (1)에 의해서 유속이 빨라짐에 따라서 지수함수로 증가 한다. 유속 약 $1.1 \mathrm{~m} / \mathrm{s}$ 에서 항력이 추력보다 커지는 지점으로 ROVO-2 ROV의 운용 한계 유속을 나타낸다. 시범조사해역의 조금 물때 최대유속은 $0.5 \mathrm{~m} / \mathrm{s}$ 로 나왔다. 또한, 수심이 $10 \mathrm{~m}$ 정도 인 시범조사해역을 고려할 때, 시범조사시 운영할 ROVO-2 ROV 의 추진기 추력은 현장에서 충분한 여유를 가질 것으로 계산되 었다. 추가로 다양한 ROV의 사양을 Power \& Drag simulation 한 결과를 본 논문의 부록 $\mathrm{B}$ 의 Fig. $\mathrm{B} 1$ 과 Fig. $\mathrm{B} 2$ 에 추가했다. Fig. 6 과 같이 시범조사에 사용될 ROVO-2 ROV는 가운데 내압유리 구에 안에 위치한 Pan/Tilt HD camera 1기와 양쪽 LED 램프 2기 가 설치되어 있으며, Blueview 2D 이미징 소나(모델: M900-130) 가 설치되어 있다. 소형 ROV의 USBL 항법데이터를 취득하기 위한 센서로 Sonardyne사의 Scout coastal transponder를 설치했다.

\section{3 운영계획}

3 단계 운영 계획은 소형 $\mathrm{ROV}$ 가 선정된 상태에서 한 지점을 조사하기 위한 육상과 해상에서 이뤄지는 모든 작업에 대한 계 획을 말한다. 운영계획을 통해 전체 소요 시간, 비용, 인력에 대 한 예측이 가능하며, 계획에는 해상 상황을 우선 고려하여 선박 운용계획을 수립한 이후 역산으로 1단계부터 계획을 수립한다.

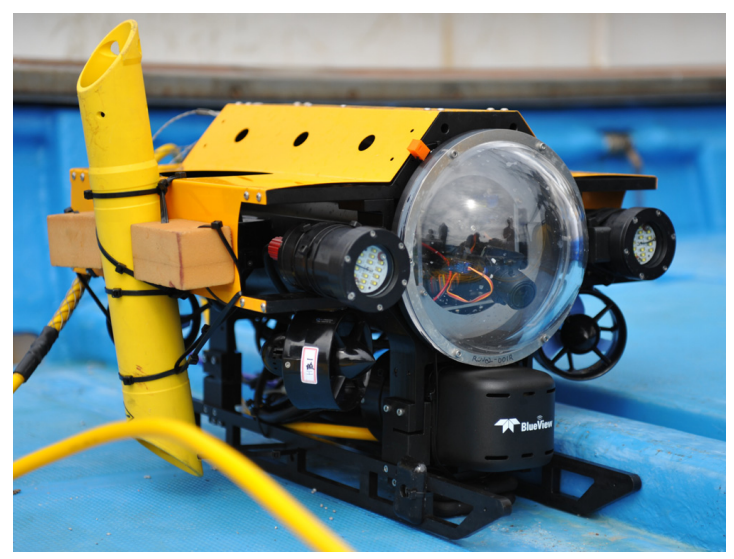

Fig. 6 Photo of ROVO-2 model 
Table 3 Operating plan for pilot survey

\begin{tabular}{ccc}
\hline \hline Step & Work contents & Working days \\
\hline 1 & Temporary work & $(2)$ \\
$1-1$ & Preparation for operation & 1 \\
$1-2$ & Move to stte & 1 \\
2 & ROV install and operation & $(3)$ \\
$2-1$ & Mobilization & 1 \\
$2-2$ & Operating ROV(in site) & 1 \\
$2-3$ & Demobilization & 1 \\
3 & Data processing & $(2)$ \\
$3-1$ & Data download & 0.5 \\
$3-2$ & Post processing & 1.5 \\
4 & Report & $(2)$ \\
$4-1$ & Report results & 1.5 \\
$4-2$ & On completion of the check & 0.5 \\
\hline
\end{tabular}

Table 3은 이번 시범조사를 수행하기 위해 작성한 계획이며, 상 세한 업무내용과 체크리스트는 생략했다.

Fig. 7은 계획 단계에서 ROV 운영 업체에서 제안한 소형 $\mathrm{ROV}$ 의 운영 모식도이다. 강한 조류에 대비해서 Clamp weight를 운용하는 시스템으로 설계하였고, 수직으로 내려가는 테더케이 블은 Clamp weight의 연결라인에 의해 구속된다. Clamp weight 의 일정 높이로부터 반경 $20 \mathrm{~m}$ 에서 $40 \mathrm{~m}$ 까지 테더케이블의 길이 조절이 가능하다. 이 방법의 장점은 수심 깊이만큼 수직으로 내 려가는 케이블의 유체저항이 ROV에 전달되지 않아 비교적 강 조류 환경에서 $\mathrm{ROV}$ 운영이 가능한 특징이 있다. 그렇지만, 진 수와 인양 시간이 충분히 필요하며, 지원모선이 앵커링하고 있 지 않은 상태에서 ROV 운영은 선박의 위치 의존도가 높다는 단점이 있다. 본 실험에서 사용할 지원모선은 선박위치와 선수 각(Heading) 정보를 위한 두 개의 DGPS 안테나와 선박에서 $\mathrm{ROV}$ 의 수중 정밀위치를 모니터링하기 위한 USBL 트랜스폰더 의 설치가 요구되어 진다. 이와 함께, $\mathrm{ROV}$ 운용관련 컴퓨터와 모니터 등이 설치되어야 하며, 수중에 Clamp Wight등의 물체를 진수.인양할 수 있는 지원모선이 필요하다. 본 연구에서는 일반

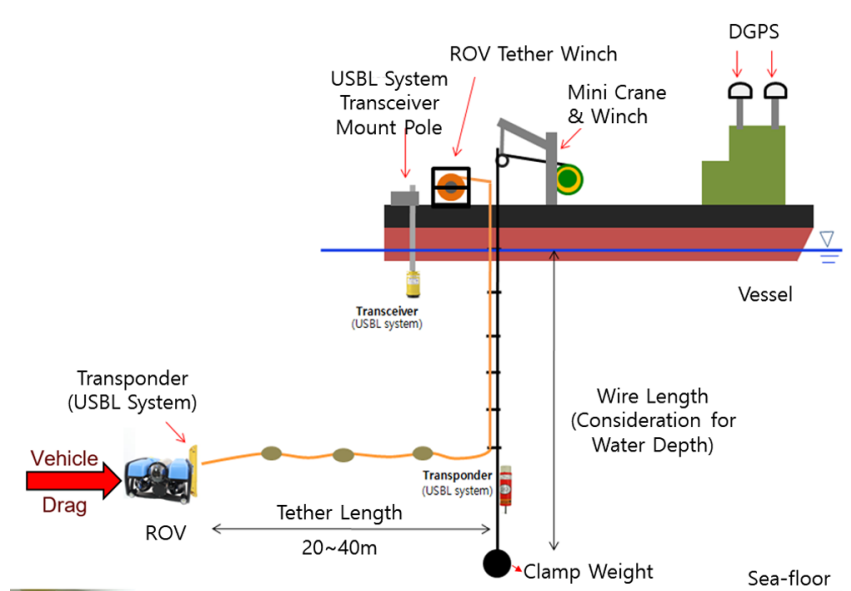

Fig. 7 ROVO-2 ROV operating concept
적으로 구하기 쉬운 4 톤급 낚시어선을 소형 $\mathrm{ROV}$ 의 지원모선으 로 선정했다.

\subsection{ROV 운영}

서해에서 소형 $\mathrm{ROV}$ 를 운영하기에는 유속이 느릴수록 유리하 다. 2018년 9월 18일은 이 달의 무시 물때로 가장 유속이 느린 날이며, 정조 시간에 맞춰 시범조사를 수행하였다. Table 3에서 설명한 운영계획을 이용한 실제 운영에는 Table 4 와 같이 총 9 일이 소요 되었다. ROV 설치 및 운영에 3 일이 계획되어 있었지 만, 실제는 2 일이 소요 되어 전체 운영일수로는 하루가 짧아졌 다. 그러나 영상이미지와 소나데이터의 분석에 1 일이 추가 소요 되어 전체적으로 동일한 9일이 소요되는 것으로 나타났다.

일반적인 과학탐사용 $\mathrm{ROV}$ 운영 결과로는 ROV video $\log$, ROV dive $\log$, 선박항해 Log, Mission sensor $\log$ 가 원본 데이터 와 함께 정리되지만, 소형 ROV의 운영 특성상 모든 $\log$ 는 항법 데이터와 영상데이터, 미션센서(이미징 소나, 멀티빔 등) 데이터 의 원본을 저장하는 것으로 갈음하는 것이 운영 투입 인원대비 장비의 원활한 운영에 긍정적일 것으로 판단된다. 갈음 조건으 로는 다음의 두 가지가 필수적이다. 하나는 항법데이터는 항법

Table 4 Comparison of operating plan vs. actual days for pilot survey

\begin{tabular}{ccc}
\hline \hline Step & Work contents & $\begin{array}{c}\text { Working days } \\
\text { (Expected / Actual) }\end{array}$ \\
\hline 1 & Temporary work & $2 / 2$ \\
$1-1$ & Preparation for operation & $15^{\text {th }}$ Sep. 2018 \\
$1-2$ & Move to site & $16^{\text {th }}$ Sep. 2018 \\
2 & ROV install and operation & $3 / 2$ \\
$2-1$ & Mobilization & $17^{\text {th }}$ Sep. 2018 \\
$2-2$ & Operating ROV(in site) & $18^{\text {th }}$ Sep. 2018 \\
$2-3$ & Demobilization & $18^{\text {th }}$ Sep. 2018 \\
3 & Data processing & $2 / 3$ \\
$3-1$ & Data download & $19^{\text {th }}$ Sep. 2018 \\
$3-2$ & Post processing & $20^{\text {th }}$ Sep. 2018 \\
4 & Report & $21^{\text {st }}$ Sep. 2018 \\
$4-1$ & Report results & $2 / 2$ \\
$4-2$ & On completion of the check & $24^{\text {th }}$ Sep. 2018 \\
\hline
\end{tabular}

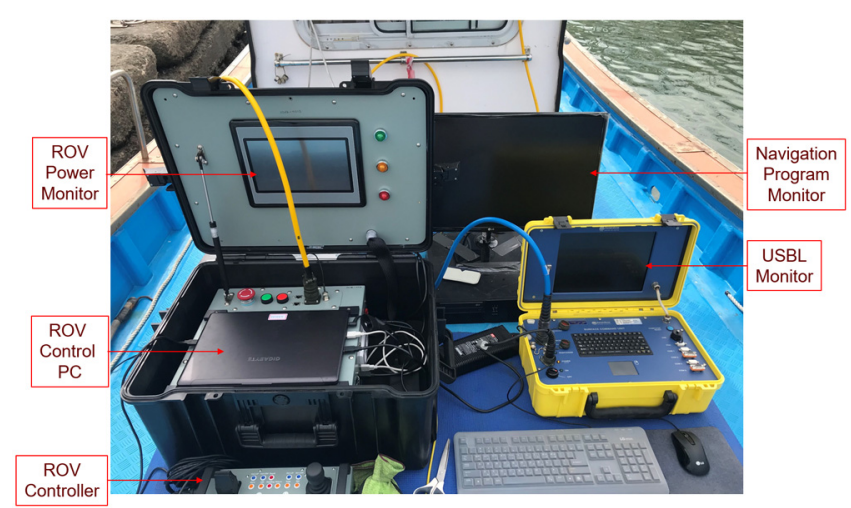

Fig. 8 Pilot consol(left), navigator console(right) 
프로그램에서 저장된 데이터를 Playback 가능하여야 하고, 다른 하나는 $\mathrm{ROV}$ 운용에 사용되는 모든 $\mathrm{PC}$ 와 센서는 운용 전 시간 동기화 작업을 수행하는 것이다. 아래 Fig. 8은 선상에 설치된 소형 $\mathrm{ROV}$ 제어시스템이다. 좌측은 조종사(ROV operator)의 위 치로 전원 모니터, $\mathrm{ROV}$ 조종 $\mathrm{PC}$ 와 그 아래로 $\mathrm{ROV}$ 조이스틱이 있고, 우측은 항해사(Navigator)의 위치로 USBL 모니터와 항법 프로그램인 Quincy 프로그램 운용 컴퓨터가 있다.

\section{5 식별보고서 작성}

논문에서 제안한 IDEF0 모델링의 마지막 5단계에서는 소형 $\mathrm{ROV}$ 시범조사를 통해 취득한 $\mathrm{HD}$ 카메라 영상, 이미징 소나 영 상, 항법 프로그램 데이터를 이용해 위험물에 대한 식별결과를 정리하는 것이다. Fig. 9의 좌측 그림은 위험물 대상을 ROV로 조사할 때의 항법프로그램 장면이다. 좌측 그림에서 우측 상부 의 선박과 위험물 대상 주변을 조사하던 ROV의 USBL 위치데 이터 누적 신호를 흰색 점들로 나타냈다.

서해는 육상에서 흘러 내려오는 부유물이 많은 해역으로 빛 의 반사(Reflection), 굴절(Refraction), 회절(Diffraction), 산란 (Scattering)에 의해 정밀한 영상 촬영이 어려운 곳이다. 이런 곳 에서는 정조 시간에 조사하는 것이 좋은 영상을 획득하는데 유 리하며, 소나를 이용하는 것이 시각 센서의 대안이 될 수 있다. 시범조사에서 식별 대상을 촬영한 영상중 화질이 좋은 영상을 캡쳐하여 아래의 Fig. 10과 Fig. 11에 나타냈다. Fig. 10은 위험 물의 외부 가장자리를 조사하던 사진으로 ROV의 선수각 148.3 도 방향(위험물의 북쪽에서 5시 방향)으로 촬영된 영상임을 자 막으로 알 수 있다. 가장자리는 계단모양의 층이 나 있는 것 또 한 확인할 수 있다. Fig. 11은 위험물 내부 가장자리를 촬영한

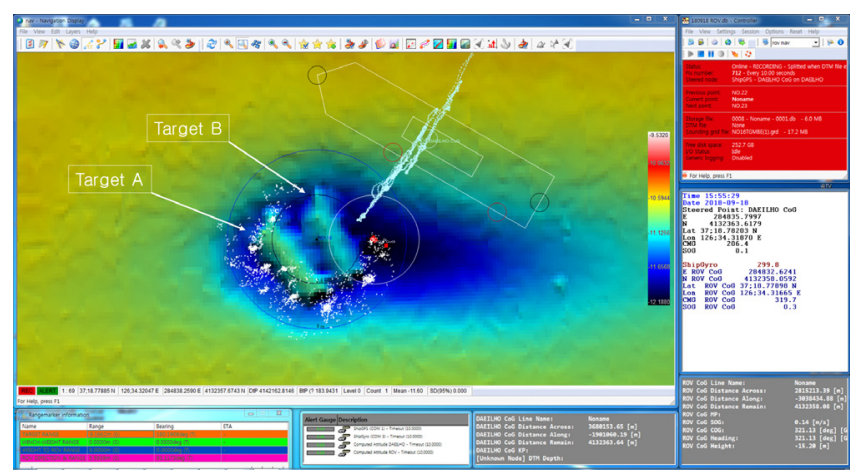

Fig. 9 Navigation program

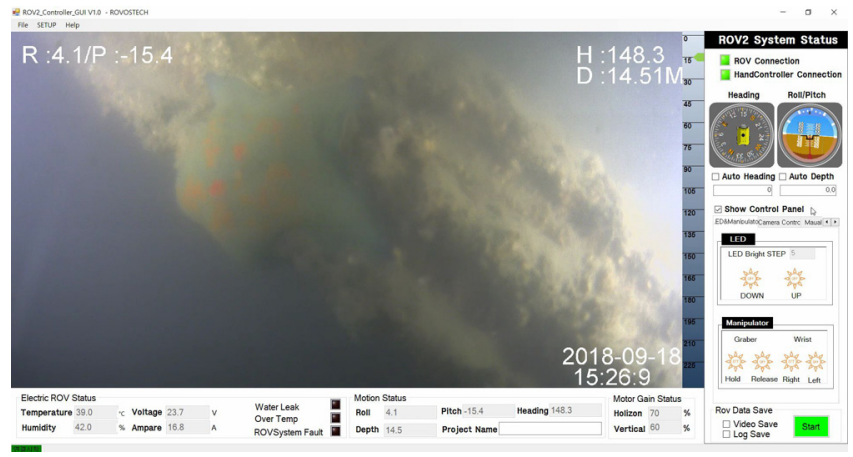

Fig. 10 Captured image of outside border displayed in pilot consol

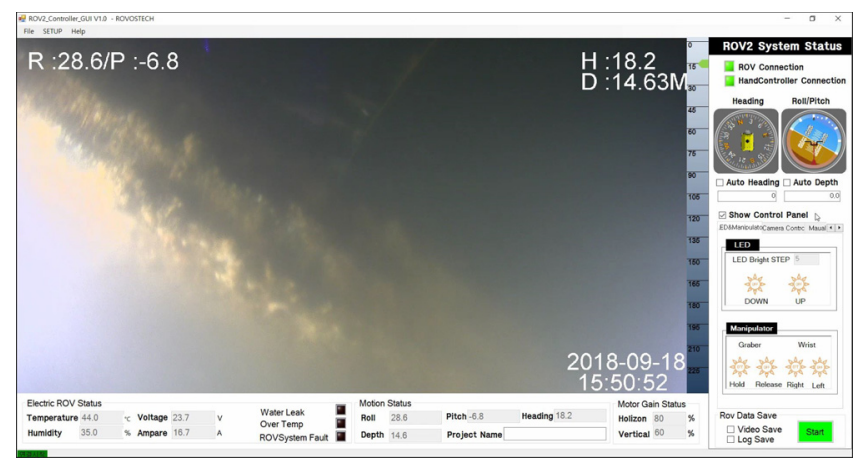

Fig. 11 Captured image of inside border displayed in pilot consol

영상으로 선수각 18.2도 방향(위험물 남쪽에서 1시 방향)으로 촬 영된 영상이다. 내부에도 계단모양의 층이 나 있는 것을 확인했다.

Fig. 3의 우측과 Fig. 9에 표시된 두 개의 미식별 위험물 주변 은 세굴(Scouring)현상이 발생된 것을 확인할 수 있다. 세굴은 수중에 인공구조물 설치 시 강한 유체에 의해 발생되는 현상으 로 위험물 주변에 흙이 많이 유실된 것으로 보아 무게가 상당 할 것으로 추정할 수 있다. 멀티빔 소나는 수면의 선박에서 지 구중심 방향으로 음파를 주사하여 고도를 측정하는 방식으로 대상물을 여러 개의 점(Point)으로 표현하는 특징이 있지만, 측 면의 정보 취득은 불가능하다. 본 시범 조사에서는 소형 $\mathrm{ROV}$ 에 이미징 소나를 설치하여 Fig. 12와 Fig. 13에서처럼 측면 이미지 를 취득할 수 있었다. Fig. 12는 Target A와 Target B 보다 높은

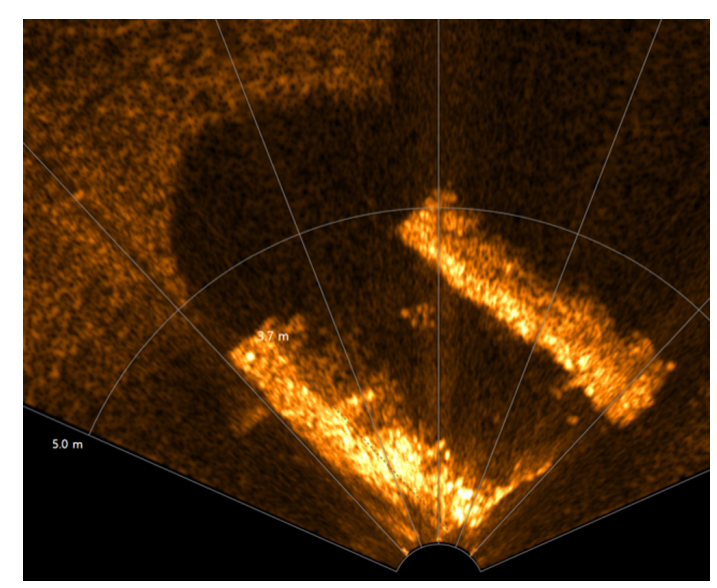

Fig. 12 Screen shot of Imaging sonar
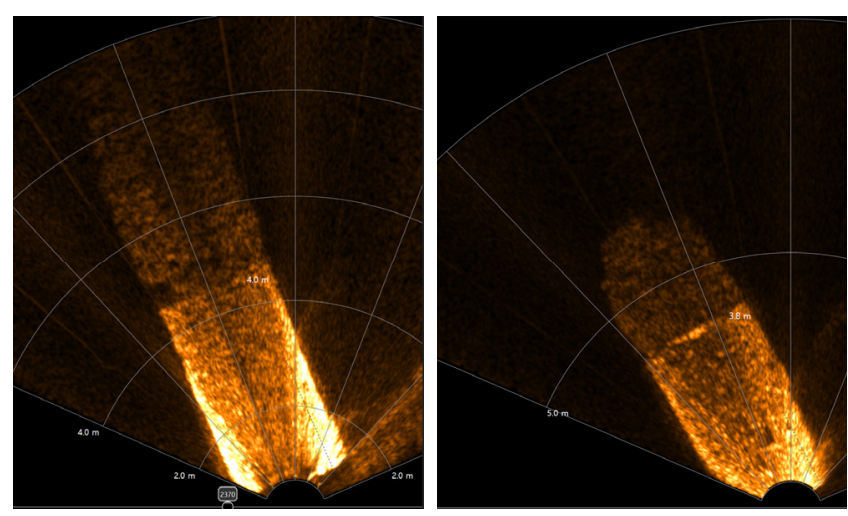

Fig. 13 Screen shot of target $\mathrm{A}($ left), target $\mathrm{B}$ (right) 


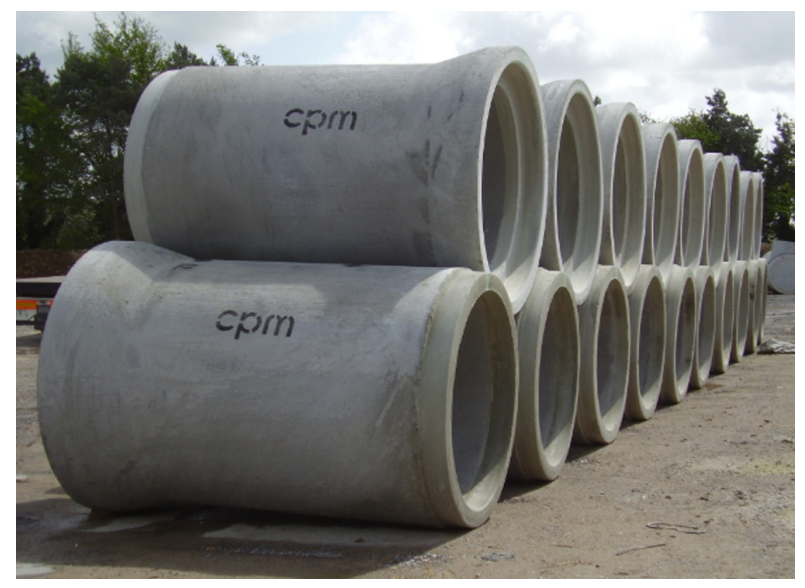

Fig. 14 Concrete pipe

고도에서 촬영된 소나영상으로 멀티빔 데이터와 유사하게 두 개의 미식별 위험물 배치상태를 확인할 수 있었다. 멀티빔과는 달리 Fig. 12의 상부에 표시된 검정색 그림자가 둥글게 나타나 므로 Target의 외형은 원통형임을 알 수 있었다. Fig. 13은 두 개 의 위험물 측면에서 각각 촬영한 데이터로 원통 형태의 Target 입구에서 내부를 관통하여 반대편으로 뻗어나가는 바닥 반사음 향을 확인할 수 있었고, 소나에 가까운 구조물 내벽에서는 강한 반사 신호가 사각형 박스 형태로 나타났다. 이미징 소나 프로그 램에서 Target $\mathrm{A}$ 는 길이 $4.0 \mathrm{~m}$, 내경 $2.2 \mathrm{~m}$ 이고, Target $\mathrm{B}$ 는 길이 3.8 미터, 내경 $2.2 \mathrm{~m}$ 로 측정 되었다.

멀티빔 데이터로 알 수 없었던 Target은 영상 촬영을 통해 내, 외벽의 가장자리에 층계구조를 가진다는 것과, 이미징 소나를 통해 내부가 비어있는 둥근 실린더 형태라는 것으로 Fig. 14 (CPM-group, 2019)와 같은 콘크리트 배관임을 알 수 있었다.

\section{4. 결 론}

No. 16번 위험물 조사를 통해 탁시계 환경에서 선박을 이용 한 멀티빔 성과로 식별이 어려웠던 대상을 소형 ROV의 이미징 소나를 이용하여 측면정보를 취득함으로써 식별이 가능했다. 이미징 소나는 실시간으로 영상을 볼 수 있어 ROV 운영자가 항법 데이터로 활용할 수 있고, 길이 측정의 정밀도가 높으므로 대상의 정밀한 크기 측정이 가능하여 소형 ROV에 있어 유용한 센서 임을 확인할 수 있었다. 또한, No. 16번 위험물은 콘크리트 배관으로 식별되었으며, 한 가지 위치 지점에서 소형 ROV를 이 용한 대상의 식별에는 예비일 1 일 2 일을 포함하여 총 10 일이 소요되는 것으로 나타났다.

$\mathrm{IDEF} 0$ 모델링의 목적은 각 단계의 모든 요구 사항과 범위를 정의하고 업무 규칙을 발견, 현행 환경의 문서화, 개선된 대안 책 개발, 그리고 다른 분석을 위한 프레임을 제공하는 것이다 (Jang and Kim, 1999). 본 논문에서는 IDEF0 모델링 기법으로 소 형 $\mathrm{ROV}$ 를 이용한 항해 위험물의 시범조사 절차와 제안한 절차
를 검증하는 시범조사 수행함으로써, 운영 표준 작성에 필요한 전반적인 사항을 점검할 수 있었다.

향후 하층 구조를 보강하고 전체 업무의 절차를 세밀하게 표 현할 필요가 있으며, 몇 회 반복하면서 절차를 수정, 업데이트 하게 된다면 제안한 표준이 소형 $\mathrm{ROV}$ 의 운영 표준으로 자리 잡을 수 있을 것으로 기대한다.

\section{후 기}

본 논문은 국립해양조사원 수탁과제인 '수중드론을 이용하여 대축척 해도에 표시된 정보를 알 수 없는 위험물을 조사하기 위한 중장기 로드맵 기획(PGS3550)'과 선박해양플랜트연구소 주요사업 '극지 빙하 탐사와 원격 모니터링을 위한 수중로봇 ICT 원천기술 개발(PES3190)'에 의해 수행되었습니다.

\section{References}

CPM-group, 2019. Concrete Pipes. [Online] Available at: $<$ https:// www.cpm-group.com/products/drainage/concrete-pipes/> [Accessed January 2019].

Doopedia, 2019. Basic Maps of the Sea. [Online] Available at: $<$ http://www.doopedia.co.kr/doopedia/master/master.do?_met hod=view\&MAS_IDX=101013000812667> [Accessed January 2019].

Dynamic Soft Inc., 2011. IDEF Methods for Knowledge Engineers and Evolutionary Enterprise. [Online] (Updated April 2011) Available at: <http://cfile5.uf.tistory.com/attach/13269C3951 408E2C09107D $>$ [Accessed January 2019].

Ismail, H.S., Rashid, M., Zhu, P., Poolton, J., 2010. A IDEF0-Based Methodology for Project Reliability Assessment. Proceddings of the 2010 IEEE International Conference on Industrial Engineering and Engineering Management, Macao China, 1568-1572. https://doi.org/10.1109/IEEM.2010.5674172

Jang, K.-J., Kim, S.-H., 1999. An Implementation Methodology for CALS/EC System Using IDEF0 and Conceptual Design in Logistics Industry. The Journal of Society for E-Business Studies, 4(1), 37-58.

Robert, D., Christ, R.L., Wernli, S., 2014. The ROV Manual. $2^{\text {nd }}$ Edition, Butterworth-Heinemann.

Rocha, F., De Tome, G., 2015. Basic mapping of the inspection process in offshore oil production facilities. OCEANS 2015MTS/IEEE, Washington, 1-8. https://doi.org/10.23919/OCEANS. 2015.7404581

The National Institute of Standards and Technology, 1993. Draft Federal Information Processing Standards Publication 183. U.S. Department of Commerce(Springfield), Virginia. 


\section{부 록}

부록 $\mathbf{A}$ 항해 위험물 수중드론 조사 IDEF0 모델링(node A-0 and A0)

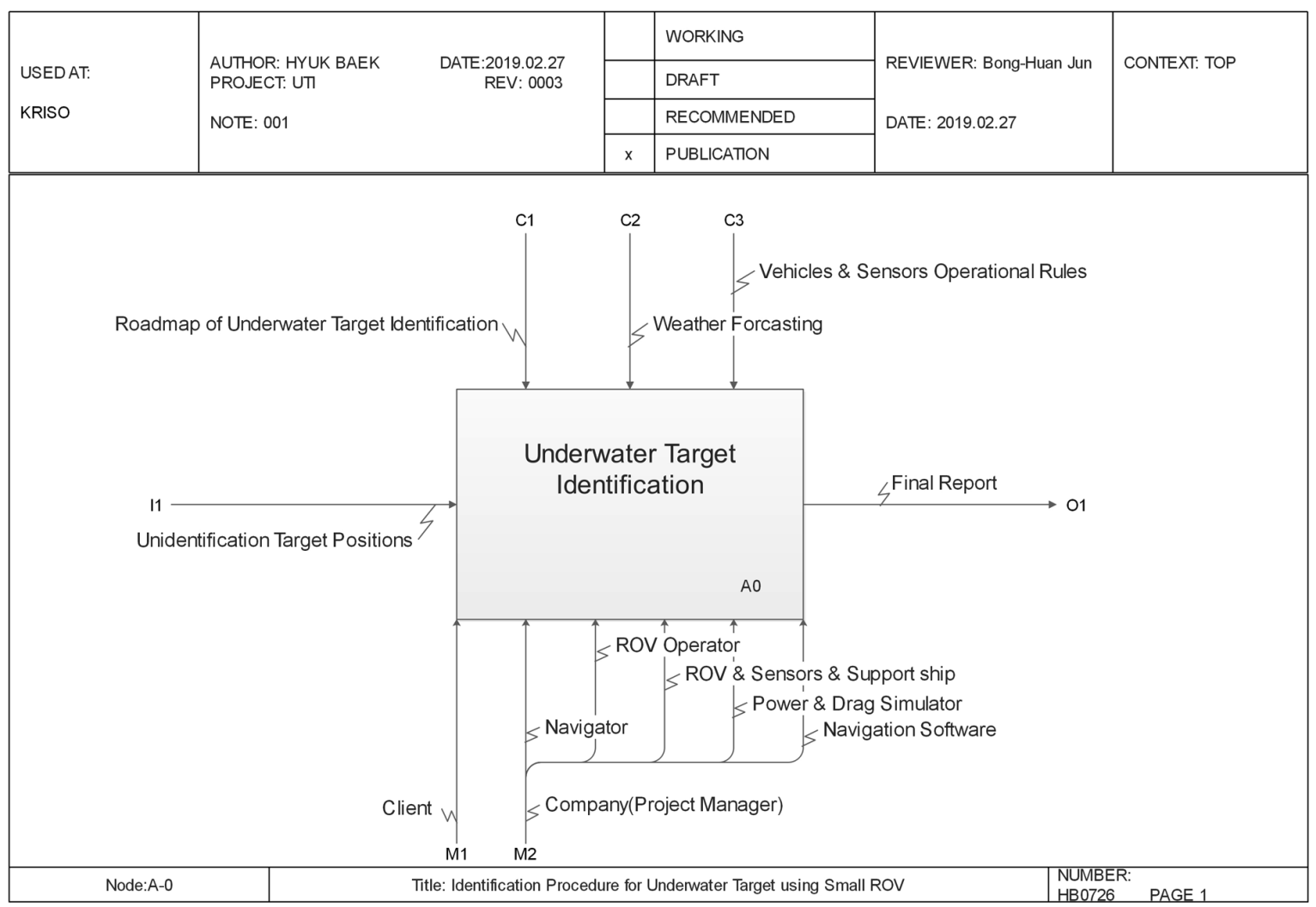

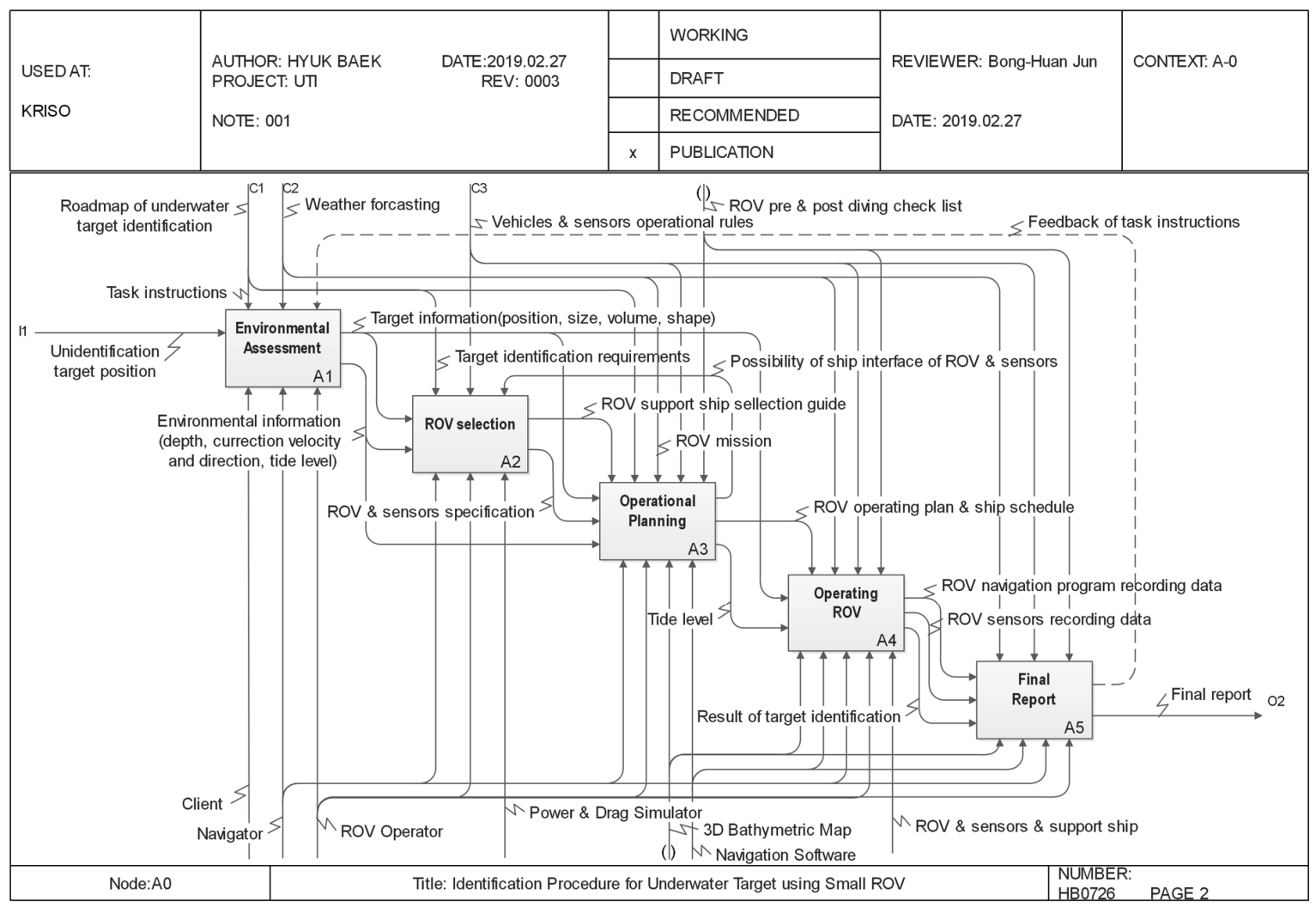

Fig. A1 Identification procedure for underwater target using small ROV 
부록 B 다양한 소형 ROV 사양으로 분석한 추력과 항력 관계

Table B1 Specifications of ROVs evaluated

\begin{tabular}{cccccccc}
\hline \hline System and Parameter & ROVO-2 & \multicolumn{5}{c}{ Large ROV A Small ROV A Small ROV B Large ROV B Small ROV C Medium ROV A } \\
\hline Max. Operation Depth [m] & 200 & 150 & 100 & 150 & 350 & 150 & 300 \\
Length [m] & 0.76 & 0.60 & 0.25 & 0.35 & 0.99 & 0.53 & 0.47 \\
Width [m] & 0.50 & 0.38 & 0.17 & 0.22 & 0.45 & 0.24 & 0.35 \\
Height [m] & 0.33 & 0.25 & 0.15 & 0.20 & 0.45 & 0.25 & 0.35 \\
Weight in Air [kg] & 19.95 & 17.69 & 1.81 & 3.62 & 31.75 & 10.88 & 18.14 \\
Thrust & 6 & 4 & 3 & 3 & 4 & 4 & 4 \\
Lateral Thrust & Yes & Yes & No & No & Yes & Yes & No \\
Propulsion Force $[\mathrm{kg}]$ & 9.97 & 11.33 & 0.90 & 2.26 & 10.43 & 4.08 & 5.44 \\
Tether Diameter [m] & 0.011 & 0.013 & 0.003 & 0.011 & 0.016 & 0.007 & 0.008 \\
Rear Camera & No & No & No & Yes & No & No & No \\
Lateral Camera & No & No & No & No & Yes & No & No \\
Power Requirement $[\mathrm{W}]$ & 2 & 3 & 1 & 1 & 3 & 1 & 3 \\
\hline
\end{tabular}

$\bigcirc$ 유속변화에 따른 추력과 테더의 항력비교

ROV CURRENT-DRAG CRUVE

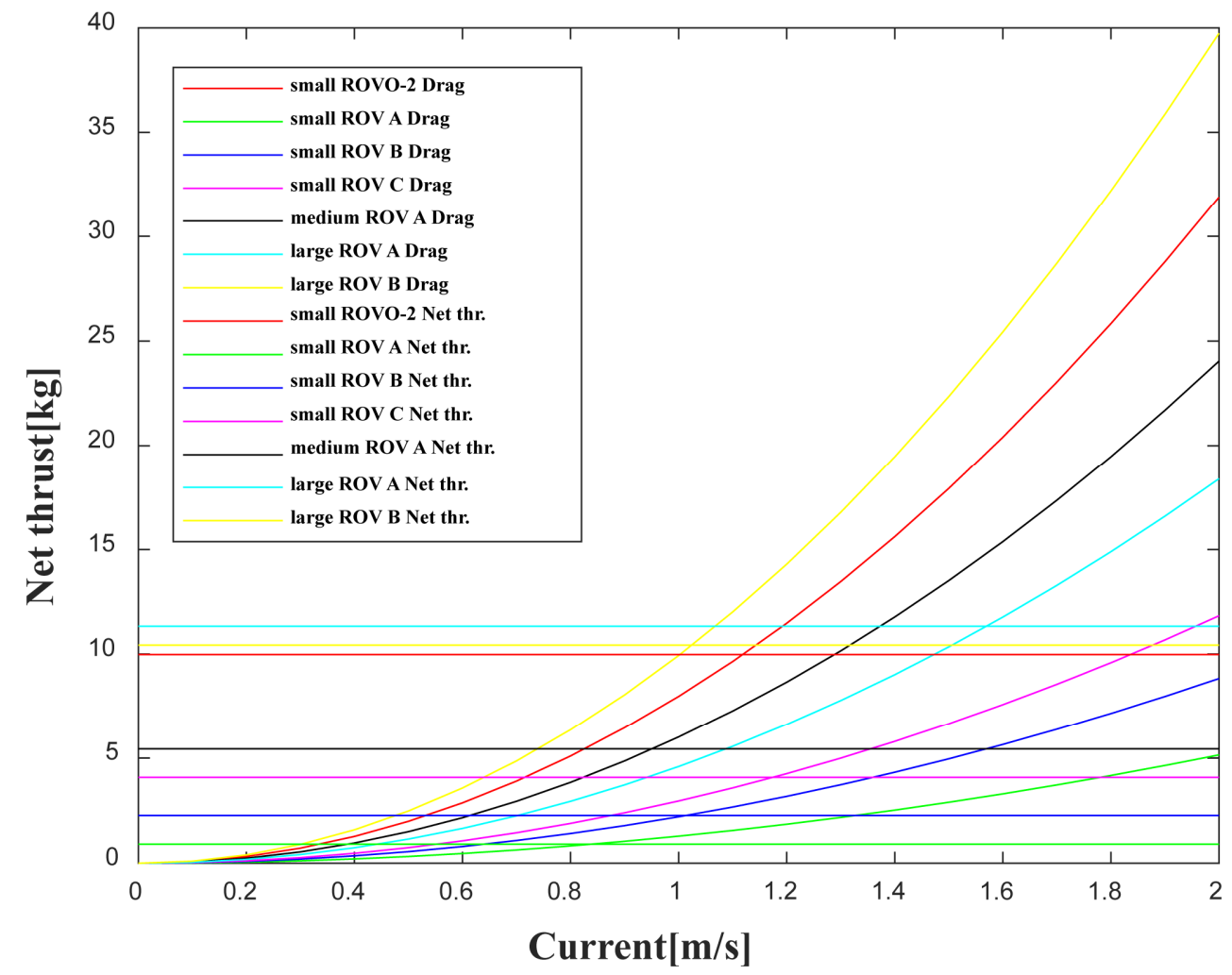

Fig. B1 Linear tether drag at varying speed with constant diameter 
$\bigcirc$ 유속 $0.5 \mathrm{~m} / \mathrm{s}$ 에서 $2 \mathrm{~m} / \mathrm{s}$ 까지 단계별 테더케이블 길이 변화에 따른 소요 추력의 변화. Net Thrust값이 0보다 작아지기 전 까지 ROV 운영가능.
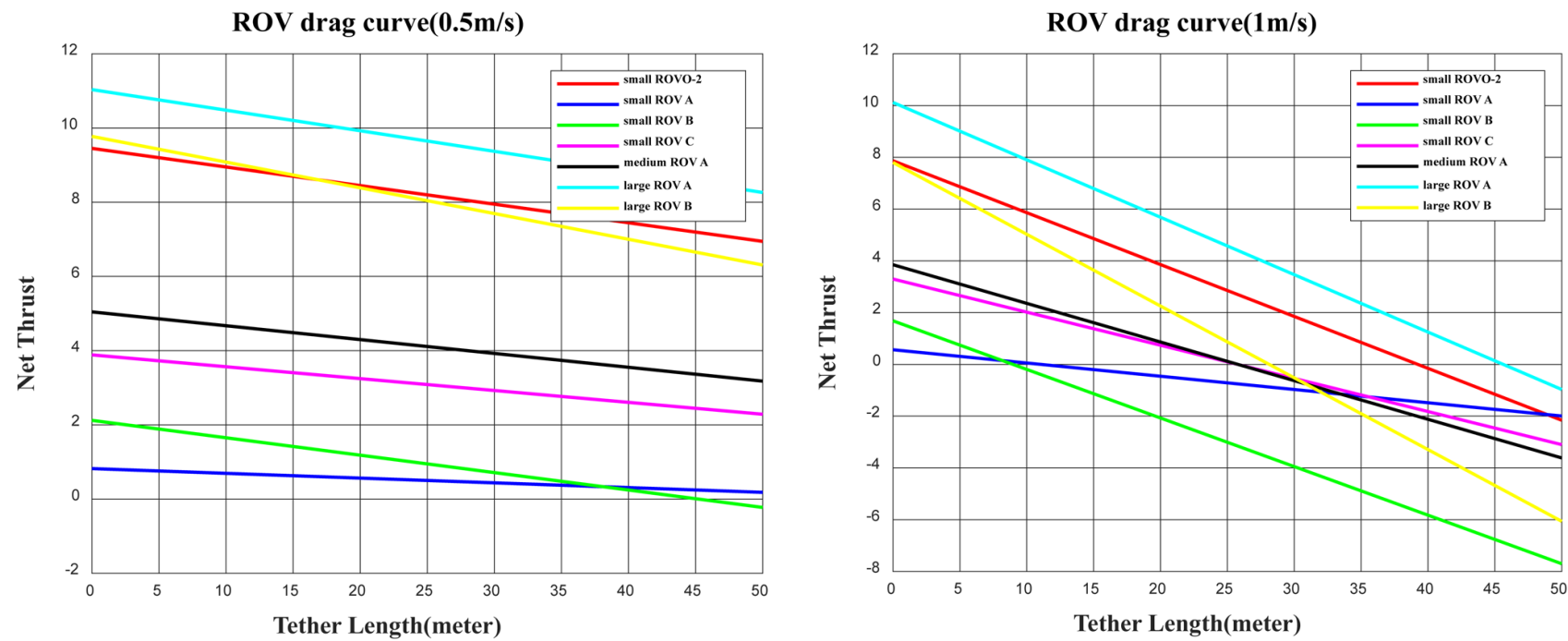

ROV drag curve $(1.5 \mathrm{~m} / \mathrm{s})$
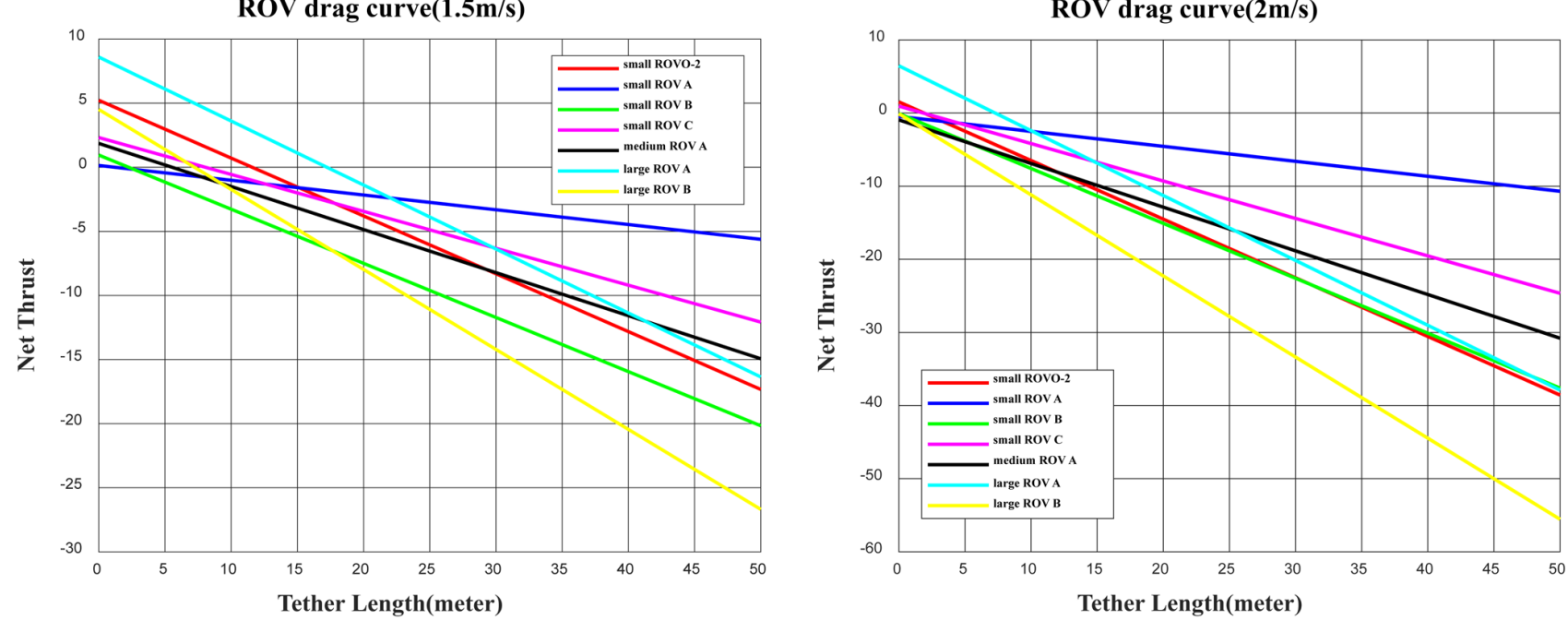

Fig. B2 Drag curves of systems tested at $0.5 \mathrm{~m} / \mathrm{s}, 1 \mathrm{~m} / \mathrm{s}, 1.5 \mathrm{~m} / \mathrm{s}, 2 \mathrm{~m} / \mathrm{s}$ 
부록 $\mathbf{C}$ 해수 유동 흐름(유향 - 유속)과 조위 예측 값

2018년도 8월 1일부터 8월 31일까지의 해수 유동 흐름(유향-유속)과 조위 예측 값을 나타냈다.

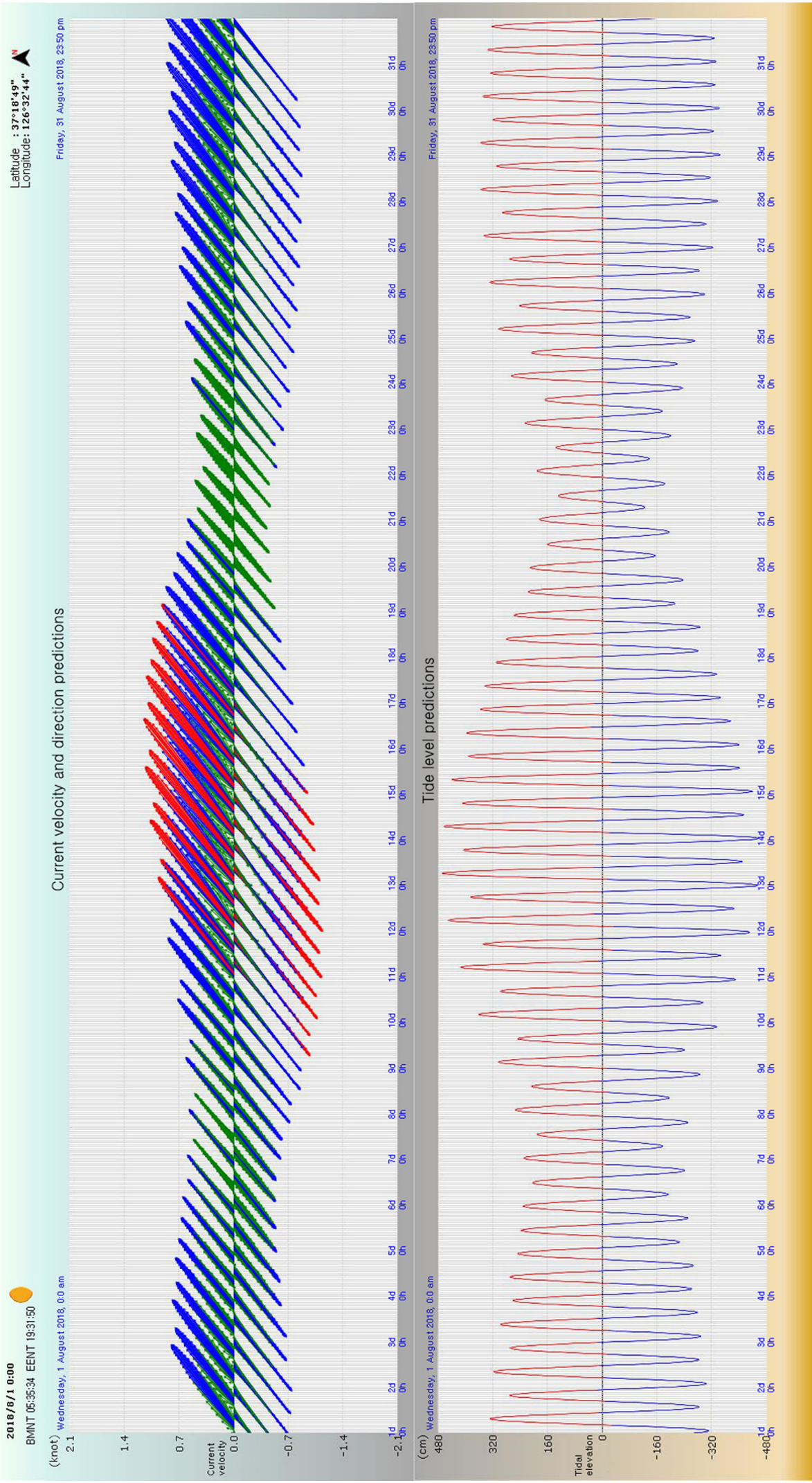

Fig. C1 Current velocity and direction predictions(upper), tide level prediction(lower) at No. 16 site 